\title{
Angiotensin receptor-neprilysin inhibitors: a new paradigm in heart failure with reduced ejection fraction
}

\author{
Authors: $\quad$ Dr Kieran F. Docherty MB ChB (Hons) \\ Prof John J.V. McMurray MD \\ Affiliation: Institute of Cardiovascular \& Medical Sciences, University of \\ Glasgow, Scotland, UK.
}

Word count: 2992

\section{Correspondence:}

Prof John J.V. McMurray

British Heart Foundation Cardiovascular Research Centre,

126 University Place,

Glasgow, G12 8TA,

Scotland, UK.

Tel: +441413303479

Fax: +44 1413306955

Email: john.mcmurray@glasgow.ac.uk 


\begin{abstract}
Despite significant advances in the last 30 years in reducing morbidity and mortality from heart failure with reduced ejection fraction (HFrEF) with pharmacological and device-based therapies, patients remain at a high risk of adverse cardiovascular outcomes.

Sacubitril/valsartan, a first-in-class angiotensin receptor-neprilysin inhibitors (ARNI), has been shown to reduce the risk of cardiovascular death or heart failure hospitalisation and improve symptoms in patients with chronic, ambulatory, symptomatic HFrEF in a large, phase 3, multicentre, international, randomised controlled trial, PARADIGM-HF, when compared to the gold-standard angiotensin converting enzyme inhibitor, enalapril. This article will review the development of sacubitril/valsartan, the evidence for its use and its current and future role in the management of HFrEF.
\end{abstract}

Keywords: heart failure, heart failure with reduced ejection fraction, renin-angiotensin aldosterone system, natriuretic peptides, neprilysin, angiotensin receptor-neprilysin inhibitor. 
"If at first you don't succeed,

Try, try, try again."

Thomas H. Palmer, The Teacher's Manual (1840)

\section{Introduction}

The publication in 1987 of the Results of the Cooperative North Scandinavian Enalapril Survival Study (CONSENSUS) heralded the beginning of 30 years of landmark randomised controlled trials (RCT) demonstrating the benefits of neurohumoral antagonists such as angiotensin converting enzyme (ACE) inhibitors, angiotensin receptor blockers (ARB), mineralocorticoid receptor antagonists (MRA) and beta-blockers in reducing the morbidity and mortality from heart failure with reduced ejection fraction (HFrEF).[1-3] Additional benefits in specific patients have also been demonstrated with implantable cardioverter defibrillators (ICD), cardiac resynchronisation therapy (CRT) and ivabradine, an inhibitor of the sinus node $l_{f}$ current.[2,3] Despite this substantial progress, significant challenges remain, with an increasingly elderly population and the improvements in the survival from myocardial infarction thought to contribute to a rising prevalence of HFrEF.[4]

Sacubitril/valsartan (previously known as LCZ696), a combined angiotensin receptorneprilysin inhibitor (ARNI), represents a significant breakthrough in the management of HFrEF. The results of the Prospective Comparison of ARNI with ACEI to Determine Impact on Global Mortality and Morbidity in Heart Failure (PARADIGM-HF) trial were the first to demonstrate efficacy of a new class of medication over the gold-standard ACE inhibitor enalapril, in reducing mortality, risk of HF hospitalisation and symptoms in patients with chronic, symptomatic, ambulatory HFrEF.[5] This article will review the development of 
sacubitril/valsartan, the evidence for its use and its current and potential future role in the management of HFrEF.

\section{Natriuretic peptides and neprilysin}

Left ventricular systolic function, most commonly due to myocardial damage as a consequence of coronary artery disease, hypertension or both, and leading to sustained, pathological activation of the renin angiotensin aldosterone system (RAAS) and sympathetic nervous system (SNS), results in the syndrome of HFrEF (Figure 1). In an effort to ameliorate the deleterious effects of this dysfunctional activation of the RAAS and SNS, the body releases a group of vasoactive peptides known as the natriuretic peptides (NP) in response to distension of the atria and ventricles. The first of these, atrial natriuretic peptide (ANP) was discovered by de Bold and colleagues in 1981 following the observation that the intravenous administration of atrial extracts in rats resulted in a potent natriuretic and diuretic response.[6] Additional beneficial vasodilatory, anti-fibrotic and anti-hypertrophic properties have also been described in ANP, B-type natriuretic peptide (BNP) and C-type natriuretic peptide (CNP).[7]

The potential to augment endogenous levels of NPs to harness their protective properties was therefore identified as a potential therapeutic strategy in HFrEF. Despite favourable haemodynamic and natriuretic effects, the administration of exogenous NPs has not been shown to reduce mortality or HF hospitalisation in patients with acutely decompensated HFrEF in a series of RCTs.[8-11] 
The alternative method to augment endogenous levels of NP is to prevent their clearance which occurs through 2 pathways; elimination via the NP clearance receptor (NPRC or NPRC3) or enzymatic degradation by neprilysin (also known as neutral endopeptidase 24.11 [NEP], enkephalinase, vasopeptidase and atriopeptidase).[12] Neprilysin is a membrane bound endopeptidase found in various tissues, but predominantly in the kidney.[13] Along with the degradation of NPs, neprilysin plays a role in the degradation of a number of other vasodilatory peptides including adrenomedullin, bradykinin, substance-P, vasoactive intestinal peptide (VIP), calcitonin gene related peptide (CGRP), glucagon-like peptide 1 (GLP-1) and apelin, all of which may be beneficial in the vasoconstrictive state of HFrEF (Figure 1).[14,15] Pharmacological inhibition of neprilysin activity, was therefore proposed as a potential therapeutic avenue to maximise the benefits of the body's own protective NP system. The question was, how best to achieve it?

\section{Neprilysin inhibitors}

The first neprilysin inhibitor, thiorphan, was reported in 1980 by Roques and colleagues, with subsequent formulations demonstrating favourable haemodynamic and hormonal responses in animal models.[16,17] Initial investigations in humans were promising; both oral (racecodotril and ecadotril) and intravenous (candoxatrilat) preparations were reported to stimulate natriuresis and diuresis along with increases in circulating plasma levels of ANP.[18-20] Unlike loop diuretics, this effect was not accompanied by a deleterious activation of the RAAS.[21] Furthermore, ecadotril and candoxatrilat resulted in reductions in pulmonary wedge pressure in patients with HFrEF.[18,20] 
However, the development of neprilysin inhibitors as monotherapy for both HFrEF and hypertension was halted after extended treatment with the oral prodrug candoxatril in patients with hypertension did not result in a sustained blood-pressure lowering effect.[22] It later transpired that the lack of any anti-hypertensive effect with neprilysin inhibitors when administered as monotherapy was secondary to the inhibition of breakdown, and therefore increased levels of, the vasoconstrictors angiotensin II and endothelin 1, thereby neutralising the augmentation of vasodilatory peptides by neprilysin inhibition.[23,24]

\section{Combined neprilysin and ACE inhibition}

On the basis of the results of the CONSENSUS and SOLVD-Treatment trials, ACE inhibitors had cemented their role as first-line disease-modifying therapy for patients with HFrEF. The addition of a neprilysin inhibitor to an ACE inhibitor (i.e. combined neprilysin and RAAS blockade) was felt to be the logical answer to the issues with neprilysin inhibitor monotherapy and this gave rise to a class of medications known as vasopeptidase inhibitors. Of these, omapatrilat was the most extensively investigated.[25] The IMPRESS (Inhibition of Metalloprotease by Omapatrilat in a Randomized Exercise and Symptoms Study in Heart Failure) trial in 573 patients with HFrEF reported a trend towards improved survival and reduced risk of admission for worsening HF with omapatrilat compared to the ACE inhibitor, lisinopril.[26] A subsequent large phase 3 RCT, the Omapatrilat versus Enalapril Randomized Trial of Utility in Reducing Events (OVERTURE), was conducted but showed that treatment with omapatrilat did not result in a significant reduction in the primary endpoint of all-cause mortality or HF hospitalisation when compared with enalapril 10mg twice daily.[27] However, potential benefit of vasopeptidase inhibitors was not excluded, with a significant $9 \%$ reduction observed in the secondary endpoint of all-cause mortality and cardiovascular 
(CV) hospitalisation. Unfortunately, the incidence of angioedema was more common with omapatrilat compared to enalapril, and this finding was replicated in a trial of omapatrilat in patients with hypertension.[28] Each of ACE and neprilysin catabolise bradykinin, and enzyme inhibition results in reduced breakdown of bradykinin. Later it was also found that omapatrilat inhibits aminopeptidase $p$, the third key enzyme involved in bradykinin degradation.[29] As well as having potent vasodilatory properties, bradykinin increases tissue permeability and fluid extravasation through increased prostaglandin concentrations. The risk of potentially life-threatening angioedema when the two (or three) enzymes were inhibited together, along with the lack of any significant benefit compared to ACE inhibitors, halted the further development of vasopeptidase inhibitors.

\section{Angiotensin receptor-neprilysin inhibitors}

Combined RAAS-neprilysin inhibition with an angiotensin receptor blocker in place of an ACE inhibitor offered the theoretical benefit of this two-pronged approach whilst circumventing the issue with dual (or triple in the case of omapatrilat) inhibition of bradykinin metabolism and risk of angioedema associated with vasopeptidase inhibitors. It was with this in mind, that led to the development of a new class of medications known as angiotensin receptorneprilysin inhibitors (ARNI).

Sacubitril/valsartan is the first-in-class ARNI, comprising of molecular moieties of valsartan (ARB) and a neprilysin inhibitor prodrug, sacubitril (AHU377).[30] Upon ingestion, sacubitril is rapidly metabolised into an active neprilysin inhibitor, sacubitrilat (LBQ657).

Pharmacokinetic and pharmacodynamic studies of the target dose of 97/103mg BD, reported equivalent plasma concentrations of valsartan as valsartan $160 \mathrm{mg} B D$ (the dose 
studied in the Valsartan Heart Failure Trial [Val-HeFT]) and rises in cyclic guanosine monophosphate (cGMP) representing an increase in ANP secondary to effective neprilysin inhibition.[31,32] Importantly, the risk of angioedema with an ARNI was thought to be lower due to the discovery that sacubitrilat does not inhibit aminopeptidase $p$, unlike omapatrilat.[29]

PARADIGM-HF compared sacubitril/valsartan (target dose 97/103mg twice daily) to the gold-standard ACE inhibitor, enalapril (target dose 10mg BD), in reducing the primary composite endpoint of CV death or HF hospitalisation in patients with chronic, ambulatory, symptomatic HFrEF.[5,33,34] Prior to randomisation, all patients underwent a mandatory 68 week active run-in period to ensure tolerance of firstly enalapril $10 \mathrm{mg} B D$, followed by sacubitril valsartan 97/103mg BD.[33] If no unacceptable side-effects occurred, patients were then randomised 1:1 to double-blind treatment with sacubitril/valsartan 97/103mg BD or enalapril 10mg BD. In March 2014, on the recommendation of the data-safety monitoring board, the trial was terminated early after a median follow-up of 27 months due to overwhelming evidence of benefit with treatment of sacubitril/valsartan compared to enalapril.

Sacubitril/valsartan was associated with a twenty percent reduction in the composite primary endpoint of $\mathrm{CV}$ death or HF hospitalisation compared to treatment with enalapril (hazard ratio [HR] 0.80; 95\% confidence interval [Cl], 0.73-0.87; $p<0.001$ [Figure 2]).[5] Significant reductions in both components of the primary endpoint, CV death and HF hospitalisation, were reported with $\mathrm{HR}$ of $0.80(95 \% \mathrm{Cl} 0.71-0.89 ; \mathrm{p}<0.001)$ and $0.79(95 \% \mathrm{Cl}$ 0.71-0.89; $p<0.001$ ), respectively (Figure 2 ). The two predominant modes of CV death, 
sudden and pump-failure death, were significantly reduced to a similar degree.[35] The secondary endpoint of all-cause mortality was also significantly reduced in the sacubitril/valsartan group ( $\mathrm{HR} 0.84 ; 95 \% \mathrm{Cl}, 0.76$ to $0.93 ; p<0.001)$.[5] The benefit seen with sacubitril/valsartan was consistent across all prespecified sub-groups.[5] These results mean that for every 1000 patients converted from enalapril to sacubitril, 46 fewer primary endpoints, 31 fewer CV deaths, 27 fewer patients hospitalised with worsening HF (and 52 fewer total HF hospitalisations), and 28 fewer deaths from any cause would occur over a median of 27 months.

Sacubitril/valsartan was well tolerated with low rates of discontinuation due to adverse effects (Figure 3).[5] The presence of an active run-in period prior to randomisation ensured initial tolerability and maximised the number of patients able to attain target doses of both study drugs. Angioedema was numerically more common with sacubitril/valsartan than enalapril (19 [0.5\%] cases vs. 10 [0.2\%]) however this difference did not reach statistical significance ( $p=0.13$ ). Additionally, no cases of angioedema with associated airway compromise were reported. There was a statistically significant difference $(p<0.001)$ in the occurrence of symptomatic hypotension with sacubitril/valsartan (14\%) compared to enalapril (9\%), but this rarely resulted in treatment discontinuation ( $0.9 \%$ vs. $0.7 \%$ respectively; $p=0.38)$. The occurrence of elevations in serum creatinine $(\geq 2.5 \mathrm{mg} / \mathrm{dl})$, potassium( $>6 \mathrm{mmol} / \mathrm{l})$, and cough was less frequent with sacubitril/valsartan than enalapril.

Subsequent to the publication of the main results of PARADIGM-HF, a variety of additional analyses have been published, giving further insight into the benefits of sacubitril/valsartan in patients with HFrEF. In an analysis of the treatment effect by age, the benefit of 
sacubitril/valsartan was seen to extend to all age groups with no difference in the risk of adverse events.[36] The efficacy of sacubitril/valsartan was consistent across the range of left ventricular ejection fractions reported, as well as the baseline risk assessed by clinical risk-scores.[37,38] Patients with HFrEF often experience recurrent admissions to hospital (approximately one-third of the PARADIGM-HF cohort) resulting in a significant burden on patients; sacubitril/valsartan not only reduces the risk of first events but also that of recurrent HF hospitalisations and/or CV death.[39] Hospital readmissions for any cause or HF occurring within 30 days of an admission were also reduced significantly by sacubitril/valsartan and this benefit persisted when 60 day readmissions were assessed.[40] Furthermore, patients randomised to sacubitril/valsartan benefited from reductions in the risk of emergency department visits and/or outpatient intensification of medical therapy.[41,42]

\section{Implementation of sacubitril/valsartan into clinical practice}

Following on from the results of PARADIGM-HF, sacubitril/valsartan was given regulatory approval for use in patients who conform to the main inclusion criteria of the trial; NYHA functional class II-IV, reduced left ventricular ejection fraction $(<40 \%)$, receiving guideline recommended treatment with a beta-blocker and MRA, a systolic blood pressure of $\geq 100$ $\mathrm{mm} \mathrm{Hg}$, estimated glomerular filtration rate $(\mathrm{eGFR}) \geq 30 \mathrm{~mL} / \mathrm{min} / 1.73 \mathrm{~m}^{2}$ and potassium $\leq 5.2 \mathrm{mmol} / \mathrm{L} .[43,44]$ The requirement for elevated NP levels for trial inclusion was omitted from the US Food and Drug Administration (FDA) and European Medicines Agency (EMA) prescribing information, reflecting that the majority of patients with HFrEF have elevated NP levels and furthermore, no interaction with treatment effect and baseline NP levels was reported.[5] 
Regulatory approval of new drugs requires confirmation of clinical efficacy in two trials with a two-sided $p$-value of $<0.05$ or alternatively, a single, large, internally consistent multicentre study with $\mathrm{p}<0.00125$. PARADIGM-HF met these criteria with overwhelming statistical evidence of efficacy; its $p$ value for the primary endpoint was 0.0000004 which is equivalent to 4-5 trials with $p$ value $<0.05$ and the likelihood of demonstrating the treatment effect observed, if in fact sacubitril/valsartan was no better than enalapril, is less than one in a million.[45] Given this, we believe it would be unethical to perform a second trial in HFrEF with sacubitril/valsartan. The degree of statistical robustness of the results of PARADIGM-HF posed an interesting quandary to the committees of international HFrEF guidelines; usually a solitary trial would be afforded a B level of evidence, however it could be argued that the results of PARADIGM-HF prove beyond reasonable doubt the efficacy of sacubitril/valsartan over enalapril at reducing morbidity and mortality in HFrEF. Furthermore, a meta-analysis combining all trials investigating dual neprilysin and RAAS inhibition in HFrEF (IMPRESS, OVERTURE and PARADIGM-HF) reported a significant pooled HR of $0.86(95 \% \mathrm{Cl} 0.76-0.97 ; p=0.013)$ in favour of dual neprilysin/RAAS inhibition compared to ACE inhibition for the composite outcome of all-cause death or HF hospitalisation.[46]

The European Society of Cardiology (ESC) and American College of Cardiology (ACC) guideline committees have both awarded a Class 1B recommendation for sacubitril/valsartan to reduce the risk of HF hospitalisation and death in HFrEF patients who remain symptomatic despite treatment with an ACE inhibitor or ARB, beta-blocker and MRA. $[2,47]$ ESC guidelines maintain that patients should be established on an ACE inhibitor 
or ARB for a minimum of one-month prior to switching to sacubitril/valsartan however ACC guidance is less strict regarding this, permitting initiation in ACE inhibitor/ARB naïve patients. $[2,44,47]$ This more liberal approach has some support from the results of the TITRATION study examining two initiation and up-titration regimens for sacubitril/valsartan; $7 \%$ of patients were ACE inhibitor/ARB naïve, reporting equivalent rates of adverse events to the total population.[48] A small proportion of this cohort were hospitalised patients (11\%) and further information regarding the safety of initiation of sacubitril/valsartan in this group will be provided by two on-going trials in patients stabilised following an acute decompensation of HFrEF (PIONEER-HF; ClinicalTrials.gov ID NCT02554890 and TRANSITION; NCT02661217). The observation in PARADIGM-HF that sacubitril/valsartan was associated with lower rates of renal dysfunction and hyperkalaemia (including in those prescribed an MRA at baseline or those who commenced an MRA during follow-up) may translate into a higher proportion of patients being able to achieve optimal RAAS inhibition (as well as the additional benefits associated with concomitant neprilysin inhibition) with initiation of an ARNI rather than an ACE inhibitor or ARB.[49]

\section{What next for sacubitril/valsartan?}

A wide-ranging portfolio of post-regulatory approval trials and observational studies are underway to further establish the role and safety of sacubitril/valsartan in clinical practice as well as helping to deepen our understanding into the mechanism of action of ARNIs. These are summarised in Table 1.

Two of these deserve further mention; the first, the Prospective Comparison of ARNI with ARB Global Outcomes in HF With Preserved Ejection Fraction (PARAGON-HF) trial will 
compare sacubitril/valsartan to valsartan in patients with heart failure and preserved ejection fraction (HFpEF) and the effect on morbidity and mortality in this group of patients in which there is currently no evidenced-based treatments.[50] This subject is further discussed by Senni in this issue [REFERENCE TO ARTICLE] and the results of PARAGON-HF are expected in 2019.

The second, the Prospective ARNI vs ACE Inhibitor Trial to Determine Superiority in Reducing Heart Failure Events After MI (PARADISE-MI; NCT02924727), will assess the effect of sacubitril/valsartan compared to ramipril in patients with left ventricular systolic dysfunction and/or pulmonary congestion following acute myocardial infarction. This population are at high risk of developing symptomatic HFrEF in the future, as evidenced by the high prevalence of prior myocardial infarction in the PARADIGM-HF cohort (43\%).[5] PARADISE-MI will provide evidence for the role of sacubitril/valsartan in the continuum of risk from acute myocardial infarction to symptomatic chronic HFrEF in a similar manner to previous trials have for ACE inhibitors and ARB.[51]

The implementation of any new medication into routine clinical practice is dependent on a variety of factors, including cost-effectiveness. A variety of economic analyses in a variety of health-care systems have been reported, with sacubitril/valsartan representing a costeffective option compared to enalapril at reducing morbidity and mortality, along with improving quality of life in patients with HFrEF.[52,53] Optimal implementation of sacubitril/valsartan in the United States of America (USA) has been projected to prevent over 28000 deaths per year.[54] Despite this, there has been significant inertia with the uptake of sacubitril/valsartan into clinical practice; in the 18 months following FDA approval, 
$<3 \%$ of patients in a USA cohort with HFrEF were prescribed sacubitril/valsartan.[55] Various reasons have been suggested to be contributing to this, including the belief that if patients are stable on an ACE inhibitor (or an ARB) then there is no reason to switch to an ARNI. Evidence from PARADIGM-HF would suggest otherwise; "stable" patients, those without a HF hospitalisation in the 3 months prior to screening or no history of HF hospitalisation, are at high risk of adverse outcomes and benefit from sacubitril/valsartan as much as recently hospitalised patients.[56]

\section{Summary}

The results of PARADIGM-HF represent the most significant breakthrough in the management of heart failure of the last decade. Sacubitril/valsartan, a first in class ARNI, is the first medication, when compared head-to-head with the gold standard ACE inhibitor, enalapril, to demonstrate superiority in reducing the risk of cardiovascular outcomes and symptoms for patients with HFrEF. We believe, therefore, that an ARNI should replace an ACE inhibitor (or an ARB) in patients with symptomatic HFrEF, a view reflected in the most recent international HF guidelines.[2,47] Adoption of this life-saving treatment, however, has been slow and the onus is on clinicians to act, in order to improve their patient's quality of life and reduce further morbidity and mortality. Ongoing studies will provide evidence regarding the role of sacubitril/valsartan in patients at high risk following a myocardial infarction (PARADISE-MI) and in patients with HFpEF (PARAGON-HF).

\section{References}

[1] J.J. V McMurray, CONSENSUS to EMPHASIS: The overwhelming evidence which makes 
blockade of the reninangiotensinaldosterone system the cornerstone of therapy for systolic heart failure, Eur. J. Heart Fail. 13 (2011) 929-936.

[2] P. Ponikowski, A.A. Voors, S.D. Anker, H. Bueno, J.G.F. Cleland, A.J.S. Coats, V. Falk, J.R. Gonzalez-Juanatey, V.P. Harjola, E.A. Jankowska, M. Jessup, C. Linde, P. Nihoyannopoulos, J.T. Parissis, B. Pieske, J.P. Riley, G.M.C. Rosano, L.M. Ruilope, F. Ruschitzka, F.H. Rutten, P. Van Der Meer, 2016 ESC Guidelines for the diagnosis and treatment of acute and chronic heart failure, Eur. Heart J. 37 (2016) 2129-2200.

[3] C.W. Yancy, M. Jessup, B. Bozkurt, J. Butler, D.E. Casey, M.H. Drazner, G.C. Fonarow, S.A. Geraci, T. Horwich, J.L. Januzzi, M.R. Johnson, E.K. Kasper, W.C. Levy, F.A. Masoudi, P.E. McBride, J.J. V McMurray, J.E. Mitchell, P.N. Peterson, B. Riegel, F. Sam, L.W. Stevenson, W.H.W. Tang, E.J. Tsai, B.L. Wilkoff, 2013 ACCF/AHA guideline for the management of heart failure: a report of the American College of Cardiology Foundation/American Heart Association Task Force on Practice Guidelines., J. Am. Coll. Cardiol. 62 (2013) e147-239.

[4] N. Conrad, A. Judge, J. Tran, H. Mohseni, D. Hedgecott, A.P. Crespillo, M. Allison, H. Hemingway, J.G. Cleland, J.J.V. McMurray, K. Rahimi, Temporal trends and patterns in heart failure incidence: A population-based study of 4 million individuals, Lancet. 391 (2017) 572-580.

[5] J.J.V. V McMurray, M. Packer, A.S. Desai, J. Gong, M.P. Lefkowitz, A.R. Rizkala, J.L. Rouleau, V.C. Shi, S.D. Solomon, K. Swedberg, M.R. Zile, PARADIGM-HF Investigators and Committees, Angiotensin-Neprilysin Inhibition versus Enalapril in Heart Failure, N. Engl. J. Med. 371 (2014) 993-1004.

[6] A.J. de Bold, H.B. Borenstein, A.T. Veress, H. Sonnenberg, A rapid and potent natriuretic response to intravenous injection of atrial myocardial extract in rats, Life Sci. 28 (1981) 89-94.

[7] L.B. Daniels, A.S. Maisel, Natriuretic peptides, J Am Coll Cardiol. 50 (2007) 2357-2368.

[8] Publication Committee for the VMAC Investigators (Vasodilatation in the Management of Acute CHF)., Intravenous nesiritide vs nitroglycerin for treatment of decompensated congestive heart failure: a randomized controlled trial., JAMA. 287 (2002) 1531-1540.

[9] C.M. O'Connor, R.C. Starling, A.F. Hernandez, P.W. Armstrong, K. Dickstein, V. Hasselblad, G.M. Heizer, M. Komajda, B.M. Massie, J.J. V McMurray, M.S. Nieminen, C.J. Reist, J.L. Rouleau, K. Swedberg, K.F. Adams, S.D. Anker, D. Atar, A. Battler, R. Botero, N.R. Bohidar, J. Butler, N. Clausell, R. Corbalán, M.R. Costanzo, U. Dahlstrom, L.I. Deckelbaum, R. Diaz, M.E. Dunlap, J.A. Ezekowitz, D. Feldman, G.M. Felker, G.C. Fonarow, D. Gennevois, S.S. Gottlieb, J.A. Hill, J.E. Hollander, J.G. Howlett, M.P. Hudson, R.D. Kociol, H. Krum, A. Laucevicius, W.C. Levy, G.F. Méndez, M. Metra, S. Mittal, B.-H. Oh, N.L. Pereira, P. Ponikowski, W.H.W. Tang, W.H. Wilson, S. Tanomsup, J.R. Teerlink, F. Triposkiadis, R.W. Troughton, A.A. Voors, D.J. Whellan, F. Zannad, R.M. Califf, http://www.nejm.org/doi/full/10.1056/NEJMoa1100171Effect of nesiritide in patients with acute decompensated heart failure.

[10] N. Hata, Y. Seino, T. Tsutamoto, S. Hiramitsu, N. Kaneko, T. Yoshikawa, H. Yokoyama, K. Tanaka, K. Mizuno, J. Nejima, M. Kinoshita, Effects of carperitide on the long-term prognosis of patients with acute decompensated chronic heart failure: the PROTECT multicenter randomized controlled study, Circ J. 72 (2008) 1787-1793.

[11] M. Packer, C. O'Connor, J.J.V. McMurray, J. Wittes, W.T. Abraham, S.D. Anker, K. Dickstein, G. Filippatos, R. Holcomb, H. Krum, A.P. Maggioni, A. Mebazaa, W.F. 
Peacock, M.C. Petrie, P. Ponikowski, F. Ruschitzka, D.J. van Veldhuisen, L.S. Kowarski, M. Schactman, J. Holzmeister, Effect of Ularitide on Cardiovascular Mortality in Acute Heart Failure, N. Engl. J. Med. 376 (2017) 1956-1964.

[12] L.R. Potter, Natriuretic peptide metabolism, clearance and degradation, FEBS J. 278 (2015) 1808-1817.

[13] M.A. Kerr, A.J. Kenny, The purification and specificity of a neutral endopeptidase from rabbit kidney brush border, Biochem. J. 137 (1974) 477-488.

[14] A. Bayes-Genis, J. Barallat, A.M. Richards, A Test in Context: Neprilysin: Function, Inhibition, and Biomarker, J. Am. Coll. Cardiol. 68 (2016) 639-653.

[15] S.M.K. McKinnie, C. Fischer, K.M.H. Tran, W. Wang, F. Mosquera, G.Y. Oudit, J.C. Vederas, The Metalloprotease Neprilysin Degrades and Inactivates Apelin Peptides, ChemBioChem. 17 (2016) 1495-1498.

[16] B.P. Roques, M.C. Fournié-zaluski, E. Soroca, J.M. Lecomte, B. Malfroy, C. Llorens, J.C. Schwartz, The enkephalinase inhibitor thiorphan shows antinociceptive activity in mice, Nature. 288 (1980) 286-288.

[17] N.B. Shepperson, P.L. Barclay, J.A. Bennett, G.M. Samuels, Inhibition of neutral endopeptidase (EC 3.4.24.11) leads to an atrial natriuretic factor-mediated natriuretic, diuretic and antihypertensive response in rodents., Clin. Sci. (Lond). 80 (1991) 265-9.

[18] J.C. Kahn, M. Patey, J.L. Dubois-Rande, P. Merlet, A. Castaigne, C. Lim-Alexandre, J.M. Lecomte, D. Duboc, C. Gros, J.C. Schwartz, Effect of sinorphan on plasma atrial natriuretic factor in congestive heart failure., Lancet. 335 (1990) 118-9.

[19] C. Gros, A. Souque, J.C. Schwartz, J. Duchier, A. Cournot, P. Baumer, J.M. Lecomte, Protection of atrial natriuretic factor against degradation: diuretic and natriuretic responses after in vivo inhibition of enkephalinase (EC 3.4.24.11) by acetorphan., Proc. Natl. Acad. Sci. U. S. A. 86 (1989) 7580-7584.

[20] D.B. Northridge, C.T. Alabaster, J.M.C. Connell, S.G. Dilly, A.F. Lever, A.G. Jardine, P.L. Barclay, H.J. Dargie, I.N. Findlay, G.M.R. Samuels, Effect of UK 69 578: a novel atriopeptidase inhibitor, Lancet. 334 (1989) 591-593.

[21] D.B. Northridge, D.E. Newby, E. Rooney, J. Norrie, H.J. Dargie, Comparison of the short-term effects of candoxatril, an orally active neutral endopeptidase inhibitor, and frusemide in the treatment of patients with chronic heart failure., Am. Heart J. 138 (1999) 1149-1157.

[22] E.G. Bevan, J.M. Connell, J. Doyle, H.A. Carmichael, D.L. Davies, A.R. Lorimer, G.T. Mclnnes, Candoxatril, a neutral endopeptidase inhibitor: efficacy and tolerability in essential hypertension., J. Hypertens. 10 (1992) 607-613.

[23] C.J. Ferro, J.C. Spratt, W.G. Haynes, D.J. Webb, Inhibition of Neutral Endopeptidase Causes Vasoconstriction of Human Resistance Vessels In Vivo, Circulation. 97 (1998) 2323-2330.

[24] J.R. Dalzell, A. Seed, C. Berry, C.J. Whelan, M.C. Petrie, N. Padmanabhan, A. Clarke, F. Biggerstaff, C. Hillier, J.J. V McMurray, Effects of neutral endopeptidase (Neprilysin) inhibition on the response to other vasoactive peptides in small human resistance arteries: Studies with thiorphan and omapatrilat, Cardiovasc. Ther. 32 (2014) 13-18.

[25] J.A. Robl, C.Q. Sun, J. Stevenson, D.E. Ryono, L.M. Simpkins, M.P. Cimarusti, T. Dejneka, W.A. Slusarchyk, S. Chao, L. Stratton, R.N. Misra, M.S. Bednarz, M.M. Asaad, H.S. Cheung, B.E. Abboa-Offei, P.L. Smith, P.D. Mathers, M. Fox, T.R. Schaeffer, A.A. Seymour, N.C. Trippodo, Dual metalloprotease inhibitors: Mercaptoacetyl-based 
fused heterocyclic dipeptide mimetics as inhibitors of angiotensin-converting enzyme and neutral endopeptidase, J. Med. Chem. 40 (1997) 1570-1577.

[26] J.L. Rouleau, M.A. Pfeffer, D.J. Stewart, D. Isaac, F. Sestier, E.K. Kerut, C.B. Porter, G. Proulx, C. Qian, A.J. Block, Comparison of vasopeptidase inhibitor, omapatrilat, and lisinopril on exercise tolerance and morbidity in patients with heart failure: IMPRESS randomised trial, Lancet. 356 (2000) 615-620.

[27] M. Packer, R.M. Califf, M. a. Konstam, H. Krum, J.J. McMurray, J.-L.L. Rouleau, K. Swedberg, Comparison of omapatrilat and enalapril in patients with chronic heart failure: The omapatrilat versus enalapril randomized trial of utility in reducing events (OVERTURE), Circulation. 106 (2002) 920-926.

[28] J.B. Kostis, M. Packer, H.R. Black, R. Schmieder, D. Henry, E. Levy, Omapatrilat and enalapril in patients with hypertension: The Omapatrilat Cardiovascular Treatment vs. Enalapril (OCTAVE) trial, Am. J. Hypertens. 17 (2004) 103-111.

[29] R.M. Fryer, J. Segreti, P.N. Banfor, D.L. Widomski, B.J. Backes, C.W. Lin, S.J. Ballaron, B.F. Cox, J.M. Trevillyan, G.A. Reinhart, T.W. Geldern, Effect of bradykinin metabolism inhibitors on evoked hypotension in rats: rank efficacy of enzymes associated with bradykinin-mediated angioedema, Br. J. Pharmacol. 153 (2009) 947-955.

[30] L. Feng, P.H. Karpinski, P. Sutton, Y. Liu, D.F. Hook, B. Hu, T.J. Blacklock, P.E. Fanwick, M. Prashad, S. Godtfredsen, C. Ziltener, LCZ696: A dual-acting sodium supramolecular complex, Tetrahedron Lett. 53 (2012) 275-276.

[31] J.N. Cohn, G. Tognoni, A randomized trial of the angiotensin-receptor blocker valsartan in chronic heart failure., N. Engl. J. Med. 345 (2001) 1667-75.

[32] J. Gu, A. Noe, P. Chandra, S. Al-Fayoumi, M. Ligueros-Saylan, R. Sarangapani, S. Maahs, G. Ksander, D.F. Rigel, A.Y. Jeng, T.H. Lin, W. Zheng, W.P. Dole, Pharmacokinetics and pharmacodynamics of LCZ696, a novel dual-acting angiotensin receptor-neprilysin inhibitor (ARNi), J Clin Pharmacol. 50 (2010) 401-414.

[33] J.J. V McMurray, M. Packer, A.S. Desai, J. Gong, M.P. Lefkowitz, A.R. Rizkala, J. Rouleau, V.C. Shi, S.D. Solomon, K. Swedberg, M.R. Zile, Dual angiotensin receptor and neprilysin inhibition as an alternative to angiotensin-converting enzyme inhibition in patients with chronic systolic heart failure: Rationale for and design of the Prospective comparison of ARNI with ACEI to Determine Impact, Eur. J. Heart Fail. 15 (2013) 1062-1073.

[34] J.J. V McMurray, M. Packer, A.S. Desai, J. Gong, M. Lefkowitz, A.R. Rizkala, J.L. Rouleau, V.C. Shi, S.D. Solomon, K. Swedberg, M.R. Zile, Baseline characteristics and treatment of patients in Prospective comparison of ARNI with ACEI to Determine Impact on Global Mortality and morbidity in heart failure trial (PARADIGM-HF), Eur. J. Heart Fail. 16 (2014) 817-825.

[35] A.S. Desai, J.J. V McMurray, M. Packer, K. Swedberg, J.L. Rouleau, F. Chen, J. Gong, A.R. Rizkala, A. Brahimi, B. Claggett, P. V Finn, L.H. Hartley, J. Liu, M. Lefkowitz, V. Shi, M.R. Zile, S.D. Solomon, Effect of the angiotensin-receptor-neprilysin inhibitor LCZ696 compared with enalapril on mode of death in heart failure patients., Eur. Heart J. 36 (2015) 1990-7.

[36] P.S. Jhund, M. Fu, E. Bayram, C.-H. Chen, M. Negrusz-Kawecka, A. Rosenthal, A.S. Desai, M.P. Lefkowitz, A.R. Rizkala, J.L. Rouleau, V.C. Shi, S.D. Solomon, K. Swedberg, M.R. Zile, J.J. V McMurray, M. Packer, PARADIGM-HF Investigators and Committees, Efficacy and safety of LCZ696 (sacubitril-valsartan) according to age: insights from PARADIGM-HF., Eur. Heart J. 36 (2015) 2576-84. 
[37] S.D. Solomon, B. Claggett, A.S. Desai, M. Packer, M. Zile, K. Swedberg, J.L. Rouleau, V.C. Shi, R.C. Starling, Ö. Kozan, A. Dukat, M.P. Lefkowitz, J.J. V McMurray, Influence of Ejection Fraction on Outcomes and Efficacy of Sacubitril/Valsartan (LCZ696) in Heart Failure with Reduced Ejection Fraction: The Prospective Comparison of ARNI with ACEI to Determine Impact on Global Mortality and Morbidity in Heart Failure (, Circ. Hear. Fail. 9 (2016) 1-6.

[38] J. Simpson, P.S. Jhund, J. Silva Cardoso, F. Martinez, A. Mosterd, F. Ramires, A.R. Rizkala, M. Senni, I. Squire, J. Gong, M.P. Lefkowitz, V.C. Shi, A.S. Desai, J.L. Rouleau, K. Swedberg, M.R. Zile, J.J.V. McMurray, M. Packer, S.D. Solomon, Comparing LCZ696 with Enalapril According to Baseline Risk Using the MAGGIC and EMPHASIS-HF Risk Scores An Analysis of Mortality and Morbidity in PARADIGM-HF, J. Am. Coll. Cardiol. 66 (2015) 2059-2071.

[39] U.M. Mogensen, J. Gong, P.S. Jhund, L. Shen, L. Køber, A.S. Desai, M.P. Lefkowitz, M. Packer, J.L. Rouleau, S.D. Solomon, B.L. Claggett, K. Swedberg, M.R. Zile, G. MuellerVelten, J.J.V. McMurray, Effect of sacubitril/valsartan on recurrent events in the Prospective comparison of ARNI with ACEI to Determine Impact on Global Mortality and morbidity in Heart Failure trial (PARADIGM-HF), Eur. J. Heart Fail. (2018).

[40] A.S. Desai, B.L. Claggett, M. Packer, M.R. Zile, J.L. Rouleau, K. Swedberg, V. Shi, M. Lefkowitz, R. Starling, J. Teerlink, J.J. V McMurray, S.D. Solomon, PARADIGM-HF Investigators, Influence of Sacubitril/Valsartan (LCZ696) on 30-Day Readmission After Heart Failure Hospitalization., J. Am. Coll. Cardiol. 68 (2016) 241-8.

[41] N. Okumura, P.S. Jhund, J. Gong, M.P. Lefkowitz, A.R. Rizkala, J.L. Rouleau, V.C. Shi, K. Swedberg, M.R. Zile, S.D. Solomon, M. Packer, J.J.V. McMurray, Importance of Clinical Worsening of Heart Failure Treated in the Outpatient Setting: Evidence From the Prospective Comparison of ARNI With ACEI to Determine Impact on Global Mortality and Morbidity in Heart Failure Trial (PARADIGM-HF), Circulation. 133 (2016) 22542262.

[42] M. Packer, J.J. McMurray, A.S. Desai, J. Gong, M.P. Lefkowitz, A.R. Rizkala, J.L. Rouleau, V.C. Shi, S.D. Solomon, K. Swedberg, M. Zile, K. Andersen, J.L. Arango, J.M. Arnold, J. Belohlávek, M. Böhm, S. Boytsov, L.J. Burgess, W. Cabrera, C. Calvo, C.H. Chen, A. Dukat, Y.C. Duarte, A. Erglis, M. Fu, E. Gomez, A. Gonzàlez-Medina, A.A. Hagège, J. Huang, T. Katova, S. Kiatchoosakun, K.S. Kim, Ö. Kozan, E.B. Llamas, F. Martinez, B. Merkely, I. Mendoza, A. Mosterd, M. Negrusz-Kawecka, K. Peuhkurinen, F.J. Ramires, J. Refsgaard, A. Rosenthal, M. Senni, A.S. Sibulo, J. Silva-Cardoso, I.B. Squire, R.C. Starling, J.R. Teerlink, J. Vanhaecke, D. Vinereanu, R.C.C. Wong, Angiotensin receptor neprilysin inhibition compared with enalapril on the risk of clinical progression in surviving patients with heart failure, Circulation. 131 (2015) 5461.

[43] European Medicines Agency, http://www.ema.europa.eu/docs/en_GB/document_library/EPAR__Product_Information/human/004062/WC500197536.pdfENTRESTO: EPAR Product information.

[44] U.S. Food and Drug Administration, https://www.accessdata.fda.gov/drugsatfda_docs/label/2015/2076200rig1s000lbl.p dfENTRESTO (sacubitril and valsartan. Highlights of prescribing information.

[45] S.J. Pocock, J.J. V McMurray, T.J. Collier, Making Sense of Statistics in Clinical Trial Reports Part 1 of a 4-Part Series on Statistics for Clinical Trials, J. Am. Coll. Cardiol. 66 
(2015) 2536-2549.

[46] S.D. Solomon, B. Claggett, J.J.V. McMurray, A.F. Hernandez, G.C. Fonarow, Combined neprilysin and renin-angiotensin system inhibition in heart failure with reduced ejection fraction: a meta-analysis, Eur. J. Heart Fail. 18 (2016) 1238-1243.

[47] C.W. Yancy, M. Jessup, B. Bozkurt, J. Butler, D.E. Casey, M.M. Colvin, M.H. Drazner, G.S. Filippatos, G.C. Fonarow, M.M. Givertz, S.M. Hollenberg, J.A. Lindenfeld, F.A. Masoudi, P.E. McBride, P.N. Peterson, L.W. Stevenson, C. Westlake, 2017 ACC/AHA/HFSA Focused Update of the 2013 ACCF/AHA Guideline for the Management of Heart Failure: A Report of the American College of Cardiology/American Heart Association Task Force on Clinical Practice Guidelines and the Heart Failure Society of Amer, 2017.

[48] M. Senni, J.J. V McMurray, R. Wachter, H.F. McIntyre, A. Reyes, I. Majercak, P. Andreka, N. Shehova-Yankova, I. Anand, M.B. Yilmaz, H. Gogia, M. Martinez-Selles, S. Fischer, Z. Zilahi, F. Cosmi, V. Gelev, E. Galve, J.J. Gómez-Doblas, J. Nociar, M. Radomska, B. Sokolova, M. Volterrani, A. Sarkar, B. Reimund, F. Chen, A. Charney, Initiating sacubitril/valsartan (LCZ696) in heart failure: results of TITRATION, a doubleblind, randomized comparison of two uptitration regimens, Eur. J. Heart Fail. 18 (2016) 1193-1202.

[49] A.S. Desai, O. Vardeny, B. Claggett, J.J.V. McMurray, M. Packer, K. Swedberg, J.L. Rouleau, M.R. Zile, M. Lefkowitz, V. Shi, S.D. Solomon, Reduced Risk of hyperkalemia during treatment of heart failure with mineralocorticoid receptor antagonists by use of sacubitril/valsartan compared with enalapril: A secondary analysis of the PARADIGM-HF trial, JAMA Cardiol. 2 (2017) 79-85.

[50] S.D. Solomon, A.R. Rizkala, J. Gong, W. Wang, I.S. Anand, J. Ge, C.S.P. Lam, A.P. Maggioni, F. Martinez, M. Packer, M.A. Pfeffer, B. Pieske, M.M. Redfield, J.L. Rouleau, D.J. Van Veldhuisen, F. Zannad, M.R. Zile, A.S. Desai, V.C. Shi, M.P. Lefkowitz, J.J.V. McMurray, Angiotensin Receptor Neprilysin Inhibition in Heart Failure With Preserved Ejection Fraction: Rationale and Design of the PARAGON-HF Trial, JACC Hear. Fail. 5 (2017) 471-482.

[51] R. Weir, J.J. V McMurray, Treatments that improve outcome in the patient with heart failure, left ventricular systolic dysfunction, or both after acute myocardial infarction, Heart. 91 Suppl 2 (2005) ii17-20.

[52] T.A. Gaziano, G.C. Fonarow, B. Claggett, W.W. Chan, C. Deschaseaux-Voinet, S.J. Turner, J.L. Rouleau, M.R. Zile, J.J.V. McMurray, S.D. Solomon, Cost-effectiveness analysis of sacubitril/valsartan vs enalapril in patients with heart failure and reduced ejection fraction, JAMA Cardiol. 1 (2016) 666-672.

[53] J.J. V McMurray, D. Trueman, E. Hancock, M.R. Cowie, A. Briggs, M. Taylor, J. MumbyCroft, F. Woodcock, M. Lacey, R. Haroun, C. Deschaseaux, Cost-effectiveness of sacubitril/valsartan in the treatment of heart failure with reduced ejection fraction, Heart. (2017) doi: 10.1136/heartjnl-2016-310661.

[54] G.C. Fonarow, A.F. Hernandez, S.D. Solomon, C.W. Yancy, Potential mortality reduction with optimal implementation of angiotensin receptor neprilysin inhibitor therapy in heart failure, JAMA Cardiol. 1 (2016) 714-717.

[55] L.R. Sangaralingham, S.J. Sangaralingham, N.D. Shah, X. Yao, S.M. Dunlay, Adoption of Sacubitril/Valsartan for the Management of Patients With Heart Failure, Circ. Hear. Fail. 11 (2018) e004302.

[56] S.D. Solomon, B. Claggett, M. Packer, A. Desai, M.R. Zile, K. Swedberg, J. Rouleau, V. 
Shi, M. Lefkowitz, J.J.V. McMurray, Efficacy of Sacubitril/Valsartan Relative to a Prior Decompensation: The PARADIGM-HF Trial, JACC Hear. Fail. 4 (2016) 816-822. 
Table 1: Ongoing post-regulatory approval clinical trials with sacubitril/valsartan in heart failure

\begin{tabular}{|c|c|c|}
\hline $\begin{array}{l}\text { ClinicalTrials.gov } \\
\text { Identifier }\end{array}$ & Study Title & Summary \\
\hline NCT02970669 & AWAKE-HF & RCT comparing sacubitril/valsartan to enalapril and effect on measures of waking and sleep activity \\
\hline NCT02787798 & B2AN-SNS & RCT comparing sacubitril/valsartan to ACE inhibitor or ARB and effect on sympathetic nervous system activity \\
\hline NCT03359967 & CHILISALT & Open label cohort study evaluating changes in intrathoracic impedance after treatment with sacubitril/valsartan \\
\hline NCT02768298 & CLCZ696BDE01 & RCT comparing sacubitril/valsartan to enalapril and effect on exercise capacity \\
\hline NCT02916160 & ENTRESTO-SAS & $\begin{array}{l}\text { Open label cohort study in patients with sleep apnoea syndrome evaluating the effect of sacubitril/valsartan on the Apnoea Hypopnea } \\
\text { Index }\end{array}$ \\
\hline NCT02874794 & EVALUATE-HF & RCT comparing sacubitril/valsartan to enalapril and effect on aortic wall stiffness \\
\hline NCT02816736 & LIFE & RCT comparing sacubitril/valsartan to valsartan and effect on NT-proBNP levels in NYHA IV HFrEF \\
\hline NCT03190304 & NEPRIEXTol & RCT comparing sacubitril/valsartan to enalapril and effect on exercise capacity \\
\hline NCT02900378 & OUTSTEP-HF & RCT comparing sacubitril/valsartan to enalapril and effect on levels of non-sedentary physical activity measured by an accelerometer \\
\hline NCT02226120 & PARADIGM-HF Open Label & Open label cohort study evaluating safety and tolerability of sacubitril/valsartan \\
\hline NCT02924727 & PARADISE-MI & RCT comparing sacubitril/valsartan to ramipril on CV outcomes in patients post AMI with LVSD and/or pulmonary congestion \\
\hline NCT03119623 & PARADOR & RCT comparing sacubitril/valsartan to enalapril and effect on endothelial function \\
\hline NCT01920711 & PARAGON-HF & RCT comparing sacubitril/valsartan to valsartan on cardiovascular outcomes in $\mathrm{HFpEF}$ \\
\hline NCT02468232 & PARALLEL-HF & RCT comparing sacubitril/valsartan to enalapril on CV outcomes in Japanese patients \\
\hline NCT02690974 & PARASAIL & Open label cohort study describing safety and tolerability of sacubitril/valsartan \\
\hline NCT02788656 & PARENT & RCT comparing sacubitril/valsartan to ACE inhibitor or ARB and effect on pulmonary artery pressure measured by CardioMEMs \\
\hline NCT02884206 & PERSPECTIVE & RCT comparing sacubitril/valsartan to valsartan and effect on cognitive function in $\mathrm{HFpEF}$ \\
\hline NCT02554890 & PIONEER-HF & $\begin{array}{l}\text { RCT comparing sacubitril/valsartan to enalapril and effect on NT-proBNP levels in patients stabilised following hospitalisation for } \\
\text { acutely decompensated HFrEF }\end{array}$ \\
\hline NCT02687932 & PRIME & RCT comparing sacubitril/valsartan to valsartan and effect on functional mitral regurgitation severity \\
\hline NCT02887183 & PROVE-HF & $\begin{array}{l}\text { Open label cohort study exploring relationship between changes in biomarkers and cardiac remodelling parameters, patient-reported } \\
\text { outcomes and cardiovascular outcomes. }\end{array}$ \\
\hline NCT02661217 & TRANSITION & $\begin{array}{l}\text { Open label RCT comparing two modalities of treatment initiation (pre-discharge, and post-discharge) with sacubitril/valsartan in } \\
\text { patients stabilised following hospitalisation for acutely decompensated HFrEF }\end{array}$ \\
\hline NCT03300427 & TurkuPET & RCT comparing sacubitril/valsartan to valsartan and effect on cardiac oxygen consumption and efficiency of cardiac work \\
\hline NCT03168568 & VASCEND & RCT comparing sacubitril/valsartan to valsartan and effect on flow-mediated vasodilation \\
\hline
\end{tabular}


Unless otherwise specified, trial populations are patients with heart failure with reduced ejection fraction (HFrEF).

Abbreviations: $A C E$, angiotensin converting enzyme; $A M I$, acute myocardial infraction; $A R B$, angiotensin receptor blocker; CV, cardiovascular; $\mathrm{HFpEF}$, heart failure with preserved ejection fractions; LVSD, left ventricular systolic dysfunction; NT-proBNP, N-terminal pro brain natriuretic peptide; NYHA, New York Heart Association; RCT, randomised controlled trial. 
Figure 1: Neurohumoral pathway activation in heart failure with reduced ejection fraction and targets for ACE inhibitors, ARB, MRA, betablockers and ARNI.

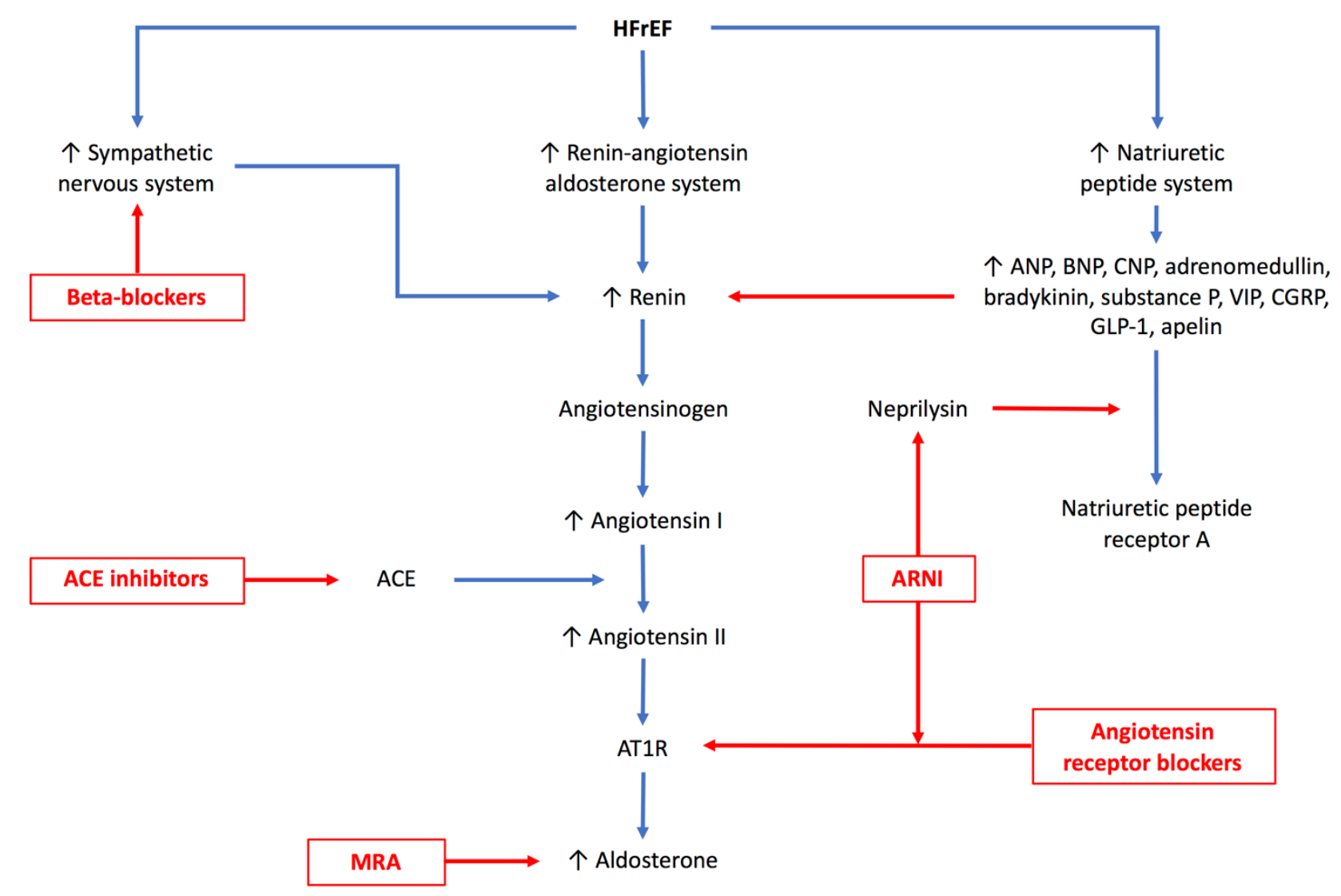

Blue arrows denote activating pathways and red arrows denote inhibitory pathways.

Abbreviations: ACE, angiotensin converting enzyme; ANP, atrial natriuretic peptide; ARNI, angiotensin receptor-neprilysin inhibitor; AT1R, angiotensin type 1 receptor; BNP, brain natriuretic peptide; CGRP, calcitonin gene related peptide; CNP, C-type natriuretic peptide; GLP-1, glucagon-like peptide 1; HFrEF, heart failure with reduced ejection fraction; MRA, mineralocorticoid receptor antagonist; VIP, vasoactive intestinal peptide. 
Figure 2: PARADIGM-HF: Kaplan-Meier Curves for outcomes according to randomised treatment
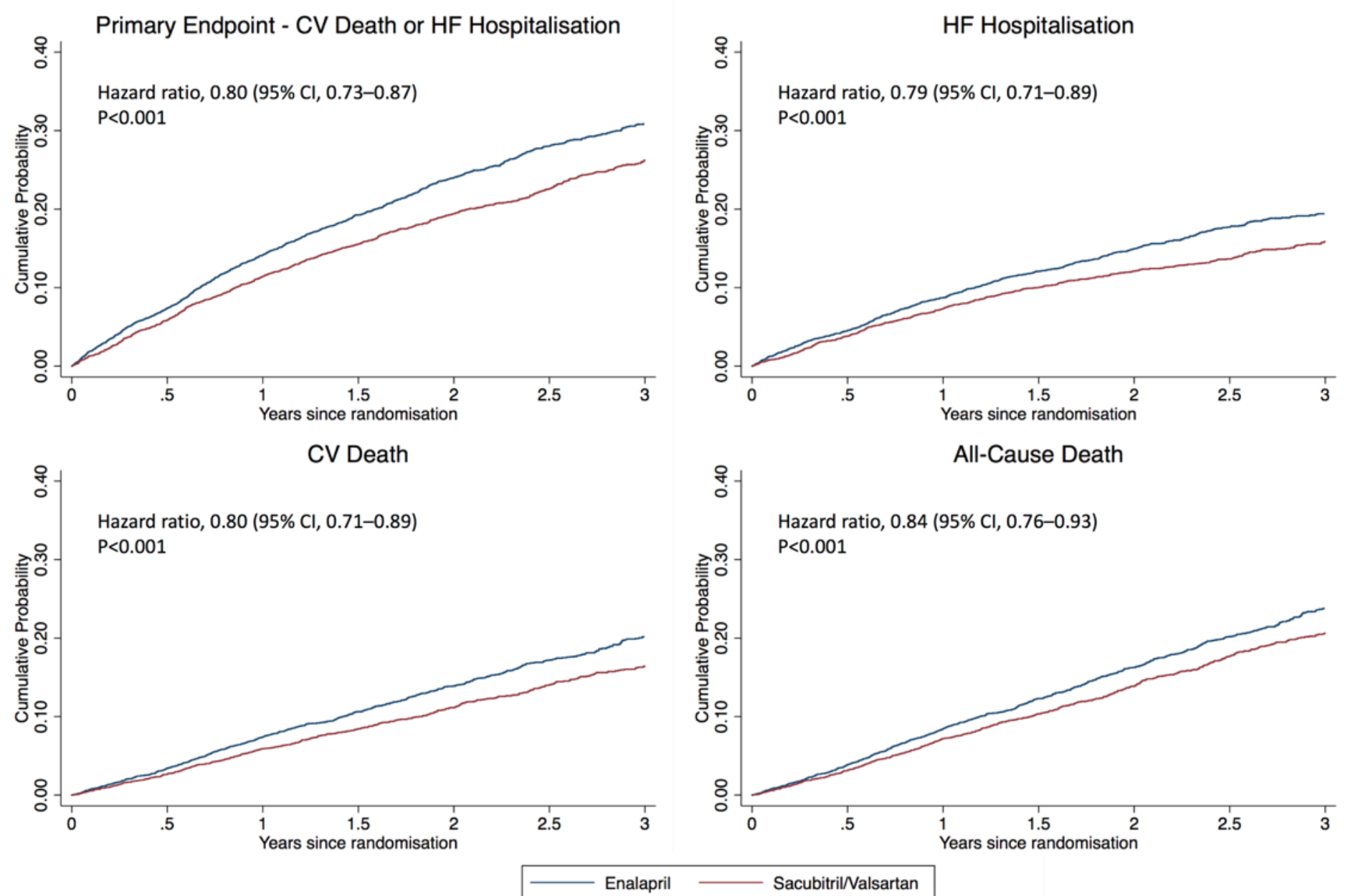

Hazard ratios, 95\% confidence intervals and two-sided $p$ values were calculated using Cox proportional-hazards models, with treatment and region as fixed-effect factors.

Abbreviations: $\mathrm{Cl}$, confidence interval; $\mathrm{CV}$, cardiovascular; $\mathrm{HF}$, heart failure. 
Figure 3: Summary of adverse events in PARADIGM-HF - comparison of sacubitril/valsartan with enalapril.

Sacubitril/valsartan $(\mathrm{n}=4187)$

- Enalapril $(\mathrm{n}=4212)$

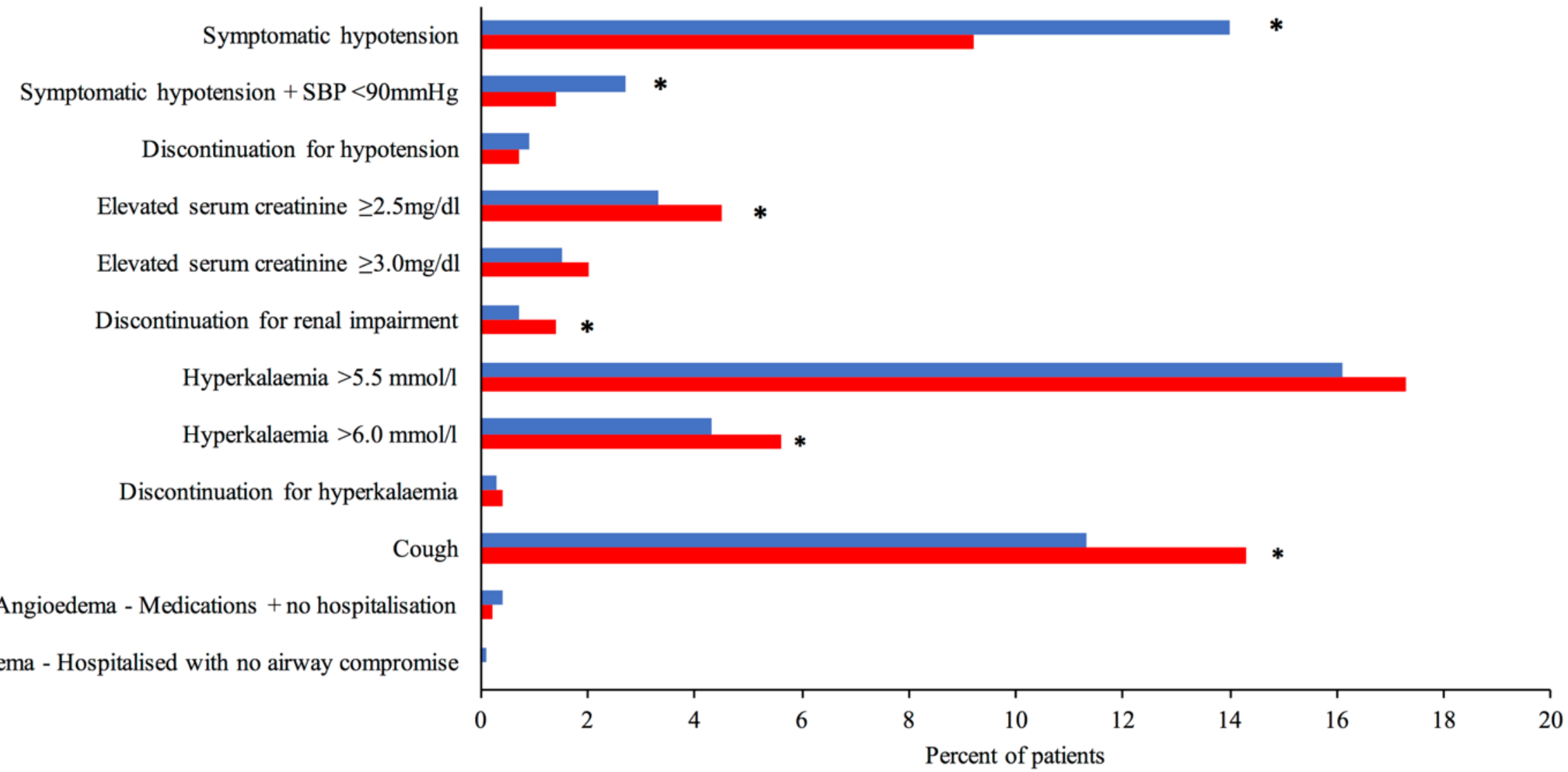

Summary of the adverse events after randomisation in PARADIGM-HF - comparison of sacubitril/valsartan with enalapril. * denotes $\mathrm{p}<0.05$. Abbreviations: SBP, systolic blood pressure. 